
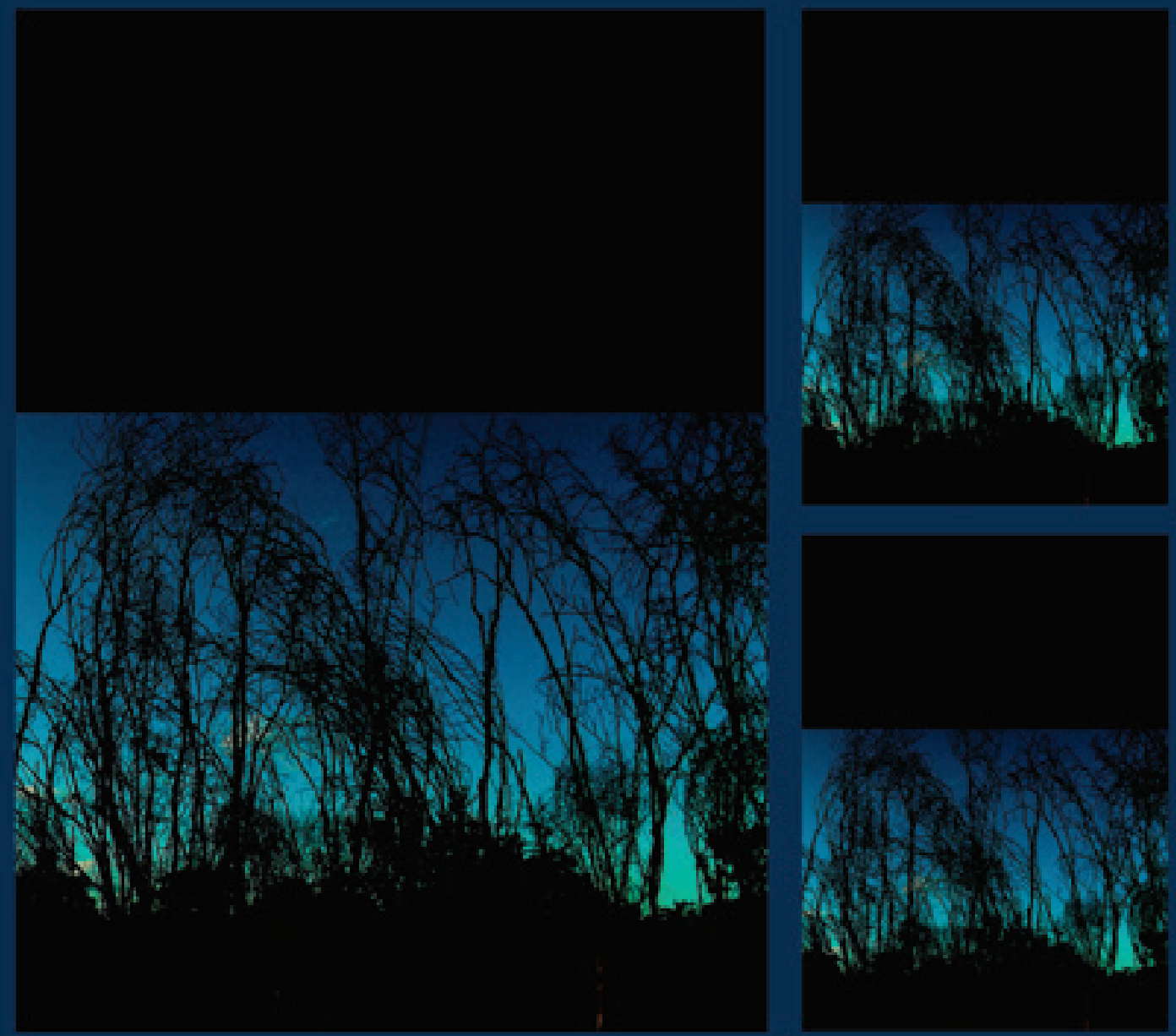


\title{
Cultura e Patrimônio: Fatores de Desenvolvimento Turístico em Luziânia-GO
}

Culture and Heritage: Tourism Development Factors in Luziânia-GO

\author{
Carla Adriana Oliveira Silva ${ }^{1}$ \\ Eloísa Pereira Barroso²
}

1 Mestre em Turismo pelo Centro de Excelência em Turismo da Universidade de Brasília, CET-UnB. Contato: carlawicca@gmail.com

2 Docente do Programa de Pós-Graduação em Turismo da Universidade de Brasília, CET-UnB. Contato: eloisabarroso@uol.com.br 


\section{RESUMO}

É de suma importância a conservação dos patrimônios históricos das cidades. Por meio deles é possível conhecer melhor a cultura e a trajetória social e política dos lugares. O turismo vem se destacando ao longo dos anos não apenas em âmbito econômico, mas também como um sujeito no ato de rememorar e na preservação dos patrimônios históricos e culturais. Luziânia é uma cidade de 266 anos, localizada no planalto central brasileiro, que merece uma atenção especial sobre o modo como o seu patrimônio histórico e cultural pode atuar no desenvolvimento do potencial turístico da cidade. Logo, o objetivo deste estudo é avaliar como a cultura pode ser determinante na preservação dos patrimônios e na promoção da experiência turística.

Palavras-chave: Cultura. Patrimônio. Turismo. Luziânia.

\section{ABSTRACT}

It is extremely important to preserve historical heritage of cities. Through them you can better know the culture and the social and political history of the places. Tourism has been increasing over the years not only in economic, but also as a subject in the act of remembering and preserving the historical and cultural heritage. Luziânia is a city of 266 years, located in the Brazilian central plateau, which deserves special attention on how its historical and cultural heritage can act in developing the tourism potential of the city. Therefore, the aim of this study is to assess how culture can be crucial in the preservation of heritage and the promotion of the tourist experience.

Keywords: Culture. Heritage. Tourism. Luziânia.

\section{INTRODUÇÃO}

O presente artigo busca discutir conceitos como cultura, patrimônio e turismo com o intuito de entender a relação entre estes e a forma como um pode influenciar diretamente na atuação do outro. Isso por entender que a compreensão dessa relação pode ser determinante no desenvolvimento do turismo de uma cidade.

Por meio de uma discussão teórica, a intenção foi investigar a cultura, os patrimônios históricos e o turismo em Luziânia, para tentar compreender de que forma estes podem contribuir para o desenvolvimento do turismo local. Isso por considerar 
que, a manutenção dos bens materiais e imateriais é primordial para a preservação da história e da memória de qualquer cidade.

Surge assim a necessidade de compreender como estes patrimônios são encarados nos dias de hoje, tanto pela comunidade que os detêm, quanto pelos órgãos governamentais e pelos visitantes que buscam nestes patrimônios, uma possibilidade de reconhecimento da identidade e da cultura local.

O município de Luziânia, localizado no Estado de Goiás/GO, trata-se de uma cidade histórica, no Planalto Central, que teve um processo de desenvolvimento urbano intimamente ligado à cultura e a religiosidade. Refletir sobre esta cidade na perspectiva do seu patrimônio cultural, relacionando ao turismo, pode possibilitar a valorização tanto do patrimônio local, como também visualizar alternativas de cunho econômico e cultural para a cidade.

A metodologia utilizada foi qualitativa, pois conforme explica Dencker (1998) pesquisar não é apenas coletar dados e informações. É pensar, refletir, interpretar, entendendo o turismo como um dos elementos que compõem a sociedade e considerando as interações das ações que venham a ser postas dentro do panorama da sociedade.

A análise do contexto teórico foi feita inicialmente por meio de uma pesquisa bibliográfica e observada nos estudos em campo, com o objetivo de compreender como à cultura e os patrimônios locais, podem intervir no desenvolvimento turístico de Luziânia. Na pesquisa em campo foi possível conhecer os principais pontos históricos, culturais e turísticos da cidade, vivenciar o estilo de vida da comunidade, e presenciar de perto a cultura que existe no município.

As cidades foram crescendo e a preocupação com a preservação dos patrimônios históricos evoluiu concomitantemente. Deve-se levar em consideração que a cidade é uma construção social que se desenvolve a partir dos seus patrimônios instituídos, e que a relação existente entre material e imaterial se torna importante para a preservação de ambos, na medida em que o patrimônio cultural também é prática social. Com o passar dos anos, um se apropria do outro, ressignificando estes espaços e estas tradições que são fundamentais para a cultura das cidades e para a identidade da comunidade local.

O turismo nunca foi encarado como uma possibilidade concreta de preservação dos patrimônios históricos e culturais de Luziânia, entretanto sua conservação é fundamental para a perpetuação da história local, e para o fortalecimento da identidade regional. Como afirma Maria Letícia Mazzuchi Ferreira (2006, p. 79) o sentido do patrimônio "é o da permanência do passado, da necessidade de resguardar algo 
significativo no campo das identidades, do desaparecimento", de modo que relacionar estes patrimônios ao desenvolvimento de um turismo planejado tende a trazer benefícios em larga escala para diversos segmentos da sociedade. Assim, uma discussão sobre a importância da cultura nesse processo se impõe necessária.

A cultura pode se manifestar de diversas formas, desde a religião, a arte, a gastronomia, até os bens arquitetônicos. Está intrínseco na natureza do ser humano viver em sociedade e, para que esta sociedade se organize, faz-se necessária a criação de regras que se formam baseadas em uma cultura, cultura esta que faz parte da vida de todas as sociedades, desde os primórdios.

Em Luziânia é nítida a totalidade da cultura presente em vários bens culturais, "O homem é essencialmente um ser de cultura (Cuche, 2002)". Ou seja, a cultura é própria do Homem. Clifford Geertz (2008, p. 10) diz que "compreender a cultura de um povo expõe a sua normalidade sem reduzir sua particularidade". $O$ autor compreende que a cultura deve ser vivenciada em sua essência, definindo o seguinte conceito para sua compreensão:

0 conceito de cultura que eu defendo, [...] é essencialmente semiótico. Acreditando, como Max Weber, que o homem é um animal amarrado a teias de significados que ele mesmo teceu, assumo a cultura como sendo essas teias e sua análise; portanto, não como uma ciência experimental em busca de leis, mas como uma ciência interpretativa, à procura do significado. (GEERTZ, 2008, p.4).

A intenção é atentar para algo tão significativo para a identidade do povo Luzianiense, trazendo à discussão para a comunidade, e também para os órgãos públicos, destacando a preocupação com a preservação da cultura da cidade, já que, "[...] na medida em que cada cultura exprime um modo único de ser homem, ela tem o direito à estima e à proteção, se estiver ameaçada (CUCHE, 2002). Por isso é preciso considerar a importância do patrimônio localizado no espaço urbano numa dimensão em que a cultura não seja ignorada.

\section{A RELAÇÃO PATRIMÔNIO E TURISMO.}

A palavra patrimônio tem sua origem no latim pater que significa pai. Ela passou a ser usada para se referir aos bens ou riquezas de uma pessoa, de uma família, de uma empresa. De acordo com Ruben George Oliven (2009, p. 77) "o termo patrimônio, em inglês - heritage - refere-se a algo que herdamos e que, por conseguinte, deve ser protegido". 
O patrimônio cultural pode ser entendido como "[...] aquela representação simbólica das identidades dos grupos humanos (CRUCES, 1998)." Nesse sentido, a identidade dos indivíduos é construída a partir de sua memória e esta, por sua vez, se constrói ao longo da história, à medida que o homem preserva hábitos, costumes, tradições e construções que, com o passar dos anos, se tornam seus patrimônios. Enfim, tudo aquilo que possui valor simbólico para uma comunidade.

Ferreira (2006, p. 79) afirma que "a palavra patrimônio, bem como memória, compõe um léxico contemporâneo de expressões cuja característica principal é a multiplicidade de sentidos e definições que a elas podem se atribuídos". Aquilo que se torna patrimônio para um povo mantém uma ligação direta com a sua história e a sua cultura, como acontece em relação aos patrimônios de Luziânia/GO, além de estes patrimônios participarem também como um bem para o consumo visual.

Por muito tempo as políticas públicas brasileiras se concentraram apenas na preservação do patrimônio edificado, especialmente nas regiões Nordeste e Sudeste. Somente após os anos 80 as outras regiões passaram a ser vistas. Em razão da promulgação da Constituição Federal de 1988, que em seus artigos 215 e 216 refere-se às responsabilidades do Poder Público com a colaboração da comunidade na promoção e proteção do patrimônio cultural brasileiro, compreendido como os bens de natureza material e imaterial, tomados individualmente ou em conjunto, portadores de referência à identidade, à ação, à memória dos diferentes grupos formadores da sociedade brasileira.

Maria Cecília Londres Fonseca (2009, p. 77) confirma que "é fundamental que se formulem e se implementem políticas que tenham como finalidade enriquecer a relação da sociedade com seus bens culturais, sem que se perca de vista os valores que justificam a preservação". Cada local tem seus próprios patrimônios e isso é o que os torna únicos. Ao buscar por novos destinos o viajante faz uma busca em sim mesmo, ele quer confirmar a ideia já construída que se tem dos lugares. Para Michel Onfray (2009, p. 55) a viagem tem uma relação muito íntima com o eu, "um dos riscos da viagem consiste em partir para verificar por si mesmo o quanto o país visitado corresponde à ideia que se faz dele".

A preservação dos patrimônios, dos costumes e das tradições de cada povo é muito importante para uma melhor compreensão da sua identidade, assim como nos ensina Stuart Hall $(2006$, p. 47) ao dizer que "no mundo moderno, as culturas nacionais em que nascemos se constituem em uma das principais fontes de identidade cultural", logo, os bens e objetos de uma família são instrumentos que refletem a sua identidade. 
Para Hall (2006, p. 38) "a identidade é realmente algo formado, ao longo do tempo, através de processos inconscientes, e não algo inato, existente na consciência no momento do nascimento". Ou seja, a identidade é constantemente construída, variando de acordo com o meio ambiente em que vivemos, o que torna possível que a sociedade se identifique com a cultura e a história herdada e procure preservá-la para as gerações futuras.

É muito importante a preservação dos patrimônios culturais, sejam eles tangíveis ou intangíveis, não só como forma de conservar o passado, mas como uma maneira de integração comunitária e preservação da cultura, que está em toda a parte, na vida em sociedade. No caso desta pesquisa, se observa ainda a relação intrínseca que o patrimônio estabelece com a atividade turística.

Não se pode deixar de relacionar esse patrimônio imaterial com o material, já que um tem o poder de ressignificar o outro, pois segundo Pereira, Silva, e Perinotto (2011, p. 370), “[...] o patrimônio não se limita apenas ao tangível e tocável. Porém, se estende para a natureza imaterial, gerando um sentimento de identidade, incentivando a promover o respeito à diversidade cultural".

$\mathrm{O}$ interesse pelos bens culturais brasileiros intangíveis tornou-se mais latente nos últimos tempos, porém, desde os anos 20, quando o escritor e ilustre representante da cultura brasileira, Mário de Andrade, realizou viagens pelo país em busca de manifestações que representassem o modo de ser, agir e de se comportar do povo brasileiro, que este tema é discutido. Ele seria, então, o pioneiro nos estudos do que viria a ser considerado o "patrimônio cultural imaterial", além de um dos criadores do órgão governamental responsável pela proteção do patrimônio cultural-IPHAN, em 1937.

A UNESCO (2003) considera a importância do patrimônio cultural imaterial como fonte de diversidade cultural e garantia de desenvolvimento sustentável. Para alguns grupos sociais (especialmente as minorias étnicas) o patrimônio imaterial carrega a sua identidade e conta parte de sua história. Dessa forma, torna-se importante assegurar a manutenção e revitalização destas tradições, que contribuem para a diversidade cultural e que estão inseridas num mundo totalmente globalizado, ficando fadadas ao desaparecimento.

No ano 2000, por meio do Decreto-Lei no 3.5519 foi instituído o Programa Nacional do Patrimônio Imaterial (PNPI) e, a partir daí, foram registrados os patrimônios imateriais no país, criando-se o Registro de Bens Culturais de Natureza Imaterial em quatro livros: 
1ㅇ - Livro de Registro dos Saberes: com os conhecimentos e modos de fazer enraizados no cotidiano das comunidades;

20 - Livro de Registro das Celebrações: com os rituais e festas que marcam a vivência coletiva do trabalho, da religiosidade, do entretenimento e de outras práticas da vida social;

3ํ- - Livro de Registro das Formas de Expressão: com as manifestações literárias, musicais, plásticas, cênicas e lúdicas;

40 - Livro de Registro dos Lugares: com os mercados, feiras, santuários, praças e demais espaços onde se concentram e reproduzem práticas culturais coletivas.

Em Luziânia, os livros com os registros dos patrimônios imateriais da cidade se encontram na Casa da Cultura Rui Carneiro. Porém, dos quatro livros existentes, dois deles ainda estão em branco, aguardando que seus patrimônios de natureza imaterial sejam reconhecidos e registrados pelo Conselho Municipal de Cultura, órgão responsável pelo registro no município.

Atualmente, no Livro dos Saberes estão registrados todos os ingredientes e o processo de fabricação da tradicional marmelada de Santa Luzia. Já no Livro das Atividades e Celebrações, está registrada a festa cultural e religiosa do Divino Espírito Santo, com um resumo da sua história, ritos, símbolos e tradições. A festa dedicada exclusivamente a Nossa Senhora do Rosário e São Benedito, que acontece em outubro, até o momento não foi registrada como patrimônio imaterial no livro do tombo da cidade, mesmo contando com a proteção espontânea da comunidade.

O poder público ainda ignora o seu registro, assim como também ignora tantos outros bens intangíveis da cidade, que continuam esquecidos pelos órgãos responsáveis. Fonseca (2009, p. 67) explica que "mesmo quando a iniciativa parte do Estado, esses valores precisam ser aceitos e constantemente reiterados pela sociedade, a partir de critérios que variam no tempo e no espaço". A autora conclui que instrumentos legais, como o tombamento, não são suficientes para garantir que um bem cumpra efetivamente o seu papel de patrimônio cultural em uma sociedade. (FONSECA, 2009).

José Reginaldo Gonçalves (2004, p. 4) afirma que "é possível, sim, preservar, por meio do registro e acompanhamento, lugares, objetos, festas, conhecimentos culinários, etc.". A preservação dos patrimônios tangíveis e intangíveis é fundamental para que se possa conhecer a história cultural, social e política de um determinado local, além de propiciar um incremento no desenvolvimento do turismo local. 


\section{TURISMO: DESENVOLVIMENTO E SUSTENTABILIDADE.}

A atividade turística vem se tornando cada vez mais atrativa. Não apenas como um instrumento para o desenvolvimento sócio-econômico, mas também como propulsor no ato de rememorar e preservar os patrimônios históricos e culturais de diferentes lugares. De acordo com Marutschka Martini Moesch (2004, p. 17), "o primeiro registro da palavra turismo remonta-se a 1800 e está no Pequeno Dicionário de Inglês Oxford: Turismo: A teoria e a prática de viajar, deslocar-se por prazer. Uso, depredação".

Nos dias de hoje o turismo é considerado um fenômeno econômico, social, humano e cultural que aproxima pessoas, lugares e cria novas relações. É uma prática que possui grande influência na conservação, desenvolvimento e preservação dos patrimônios históricos das cidades e possui uma íntima relação com a cultura. Assim, se buscou nesta pesquisa evidenciar os patrimônios tradicionais de Luziânia, na ascensão do turismo da cidade.

A prática turística é capaz de promover uma nova perspectiva de desenvolvimento social e econômico em várias localidades, oferecendo possibilidades de revitalização dos patrimônios históricos e arquitetônicos; justamente como necessita o município de Luziânia, objeto desse estudo, que não trata os seus patrimônios com o devido valor, "o público, hoje, interessa-se pelas paisagens históricas na medida em que elas são consideradas um dos fundamentos da construção da identidade (Costa, 2011)."

O turismo é uma atividade que possui a capacidade de exaltar o desenvolvimento das sociedades em várias áreas, como a econômica, a social, a política e a cultural. Nas últimas décadas tem se destacado como uma das mais importantes atividades econômicas em todo o mundo, afirmando-se como fonte fornecedora de serviços, produtos, emprego e renda.

Assim, pode-se dizer que o turismo é um fenômeno contemporâneo e de natureza complexa, cuja importância atualmente compreende os setores econômico, social e político e, deste modo, pode ser planejado na cidade de Luziânia para o desenvolvimento de todos esses aspectos, já que o que se percebe nos últimos tempos é um total descuido e despreparo por parte dos gestores, públicos e privados, quanto ao planejamento territorial da cidade, o que inviabiliza a sustentabilidade turística.

Todos os fatores que integram as relações sociais, culturais e ambientais fazem parte do objeto de estudo da sustentabilidade turística. Porém, somente a partir dos anos 70 que houve uma maior preocupação em relação aos processos sociais e culturais, além dos impactos ambientais resultantes do desenvolvimento do turismo. (Jafari, 1994). 
Em Luziânia, o que se observa, é que não há uma maior preocupação por parte dos governadores que integre os fatores culturais, ambientais e econômicos, entretanto, devemos encarar o turismo sob todos os pontos de vista que envolvem essa atividade. Por isso, turistas, moradores, órgãos públicos, empresas, planejadores e gestores turísticos devem trabalhar juntos, contribuindo e incentivando o desenvolvimento de um turismo sustentável.

Como orienta a OMT, os planejadores, empreendedores, e principalmente os gestores públicos envolvidos no desenvolvimento turístico devem incentivar e apoiar um envolvimento maior da sociedade por meio da construção de consensos. Ou seja, no planejamento, no monitoramento, na implementação e na avaliação dos projetos e programas da política de turismo.

Mário Beni (1998) define o enfoque econômico e o ecológico como os principais para a sustentabilidade turística, de maneira que um vise apenas o lado financeiro, e o outro a preservação das áreas naturais. $O$ autor cita ainda que o desenvolvimento econômico ecologicamente sustentável deva demonstrar uma sustentabilidade capaz de unir o ser humano com o meio ambiente em sua totalidade e, deste modo, consegue englobar os sistemas culturais, sociais e econômicos numa mesma perspectiva.

Este tipo de desenvolvimento é exatamente uma das necessidades de Luziânia, que tem dificuldades em agregar o seu potencial natural e cultural de forma positiva para o desenvolvimento econômico e social, alinhado ao turismo no município. Assim, Luziânia surge como uma cidade, em que grande parte do seu patrimônio histórico e cultural, tangível e intangível, está em estado de abandono, deixando que se perca no tempo algo que pode significar um potencial para o desenvolvimento turístico da cidade, além da importância histórica que estes patrimônios possuem para que as gerações futuras conheçam a sua história.

Para que o desenvolvimento da atividade turística seja satisfatório é fundamental um planejamento aprofundado de todos os aspectos que envolvem a sua ascensão, de forma a minimizar os impactos negativos e priorizar os positivos, fazendo com que a comunidade possa se sentir favorecida pelo turismo, já que a falta deste planejamento tende a criar uma relação de atrito entre turistas e autóctones, assim como nos explica Collin Michael Hall (2004) ao tratar da importância deste planejamento:

Embora o planejamento não seja uma panaceia para todos os males, quando totalmente voltado para processos ele pode minimizar impactos potencialmente negativos, maximizar retornos econômicos nos destinos e, dessa forma, estimular uma resposta mais positiva por parte da comunidade hospedeira em relação ao turismo no longo prazo (HALL, 2004, p. 29). 
Alguns autores veem o turismo sustentável como um tipo de turismo que tem um olhar diferenciado em relação ao envolvimento da comunidade. Ruschmann (1997) afirma que este tipo de turismo pode ser definido como um modelo de gerenciamento da atividade que realça a defesa dos aspectos naturais e culturais do núcleo receptor, de maneira que se evite a deterioração dos atrativos e se estimule a economia local de maneira consensual e atendendo às demandas das comunidades.

A sustentabilidade turística deve atentar-se para que a relação turista versus comunidade seja a mais harmoniosa possível. Essa relação entre autóctones e visitantes deve causar o mínimo de impacto negativo sob esta comunidade, reconhecendo seu valor nos processos participativos, visto que isso é fundamental para o desenvolvimento de um turismo com foco na preservação da cultura e da identidade.

Logo, se planejado, o turismo traz benefícios para as cidades e para os seus residentes, como vantagens econômicas, sociais, ambientais e culturais. Vale ressaltar que o estudo em Luziânia levou em consideração a importância da sustentabilidade na produção social e espacial onde se insere a atividade turística, já que isso é fundamental a sua compreensão.

Pressupõe-se que a sustentabilidade é um elemento intrínseco à organização da atividade turística e indispensável para o seu planejamento. Esse processo sustentável de desenvolvimento é a base para a ascensão e manutenção do turismo local.

\section{O TURISMO CULTURAL.}

Para Pedro Paulo Funari (2003) "todo turismo é cultural". Essa modalidade de turismo vem sendo debatido na literatura a partir da década de oitenta, surgindo vários conceitos na tentativa de defini-lo. O turismo cultural pode ser compreendido como a atividade turística cujo foco é alguma manifestação da cultura. Desta forma, Luziânia, que é considerada uma cidade histórica, agrega diversos patrimônios com potencial para alavancar esse tipo de turismo.

O documento "Diretrizes para o Desenvolvimento do Turismo Cultural", do Ministério do Turismo conceituou o turismo cultural como "a vivência do conjunto de elementos significativos do patrimônio histórico e cultural e dos eventos culturais, valorizando e promovendo os bens materiais e imateriais da cultura" (BRASIL, 2008, p. 8).

Com o fim da Segunda Guerra Mundial e o desenvolvimento dos meios de transporte, difundiu-se o chamado turismo de massa que, de acordo com Moesch (2002, p. 133), pode ser entendido como "um turismo que destrói o meio-ambiente, contribui para o desaparecimento dos usos e costumes locais e favorece a difusão da dro- 
gadição e prostituição, impedindo o desenvolvimento e o progresso dos povos".

Já o turista cultural é percebido como um visitante que, além da experiência, tem a preocupação com as consequências da sua viagem, para Brian Goodey (2002, p. 135) o turismo cultural "pressupõe um público educado e informado que compartilha com os órgãos de patrimônio uma definição sobre o que constitui lugares, eventos e coleções corretas".

A vivência histórica das comunidades, ao ser valorizado pelo turismo, enriquece a experiência do turista e reforça o sentimento de pertença local (BRASIL, 2008). Assim, o perfil do visitante predisposto a este tipo de viagem é traçado pelo Ministério do Turismo como:

O turista cultural valoriza a cultura em toda a sua complexidade e particularidade, movimentando-se em busca de ícones que representem a identidade local e a memória coletiva. Ambos os conceitos remetem a um conjunto de experiências, fatos históricos e elementos culturais comuns a um grupo ou comunidade, e que podem ser representados pelos bens culturais materiais e imateriais que compõem o patrimônio (BRASIL, 2008, p. 17).

O turismo cultural tem o poder de colaborar com o desenvolvimento das regiões e com a preservação da memória e da identidade local. Existem inúmeros motivos que levam as pessoas a praticar o turismo, as celebrações religiosas e populares, a culinária, os artesanatos, as paisagens, entre outros patrimônios tangíveis e intangíveis, que auxiliam na formulação de um turismo baseado nos valores culturais e no resgate histórico.

Isso deve ser trabalhado em Luziânia para o seu crescimento e desenvolvimento turístico, já que o município tem potencial para alavancar um turismo cultural, porém, não vem sendo tratado de forma apropriada por conta da negligência governamental e desinteresse da própria comunidade em dar valor àquilo que é seu.

Anderson Pereira Portuguez (2004, p.3) afirma que "pensar o espaço turístico a partir das formas arquitetônicas antigas, significa um esforço de interpretação do mundo vivido pelos grupos sociais que antecederam a vida moderna, o que desperta o interesse e a curiosidade dos turistas". Assim, torna-se importante essa interação do visitante com a cultura local, o que fundamenta o turismo cultural, como explica Marina Aguiar e Reinaldo Dias (2002):

[...] uma atividade de lazer educacional que contribui para aumentar a consciência do visitante e sua apreciação da cultura local em todos os seus aspectos - históricos, artísticos, etc. Além disso, é uma forma de Turismo que, entre outros objetivos, envolve a apreciação de monumentos e sítios históricos, contribuindo dessa 
forma para a manutenção e proteção do patrimônio cultural e natural da humanidade (AGUIAR E DIAS, 2002, p.133).

A atividade turística deve ter a preocupação de se implantar nas comunidades sem influenciar a cultura local, mas agindo como forma de resgate e preservação das manifestações culturais, não se permitindo que o movimento de pessoas e os interesses econômicos descaracterizem os patrimônios, pois, como nos coloca Stela Maris Murta (2002, p. 140) essa visão apenas das questões de mercado "podem transformar os locais turísticos em meros cenários e as comunidades em museus performáticos de práticas patrimoniais".

Logo, os gestores de Luziânia devem se preocupar em realizar um planejamento que vise à cidade como um todo, para assim ser possível o desenvolvimento de um turismo cultural e sustentável. Entende-se que esta sustentabilidade pode atuar diretamente na preservação dos patrimônios culturais de Luziânia, além de servirem como reflexos para o reconhecimento da identidade local.

\section{LUZIÂNIA: UM PATRIMÔNIO CULTURAL.}

Luziânia foi fundada pelo bandeirante Antônio Bueno de Azevedo, em 1746, quando este encontrou jazidas de ouro as margens do Rio São Bartolomeu atraindo, assim, inúmeras pessoas para lá, como cita o escritor luzianiense José Dilermando Meireles (1996). Logo em seguida, foi erguida uma casa de oração às margens do garimpo e fincada uma cruz que seria, então, o marco inicial da cidade e a partir de onde o arraial se desenvolveria. Anos depois a casa de oração foi destruída e erguida no mesmo local a Igreja Nossa Senhora do Rosário, que interligada a Igreja Matriz de Santa Luzia, constituem parte do núcleo histórico da cidade.

A associação do intangível com o tangível, presente no centro histórico, valorizam a cultura e a memória local, além de favorecer a ascensão do turismo neste espaço, entendendo que a expressão centro histórico, mais do que remeter para um objeto, ou para um espaço, converte-se em uma representação de alguma coisa. (PEIXOTO, 2003). Luziânia surge então como uma cidade que mantém traços do passado no seu centro histórico, que permitem uma leitura da sua história e compreensão da sua cultura.

Grande parte dos bens, ligados ao patrimônio cultural, com potencial para o desenvolvimento da atividade turística em Luziânia, está localizada no centro histórico da cidade. Lá se encontra alguns dos patrimônios materiais, como a Igreja do Rosário; a Igreja Matriz de Santa Luzia; e a Cruz do Desbravador, que é o marco inicial do povoado; além dos inúmeros casarões em estilo colonial. Ao andar por estas ruas, 
é possível ter a sensação de estar caminhando em ruas de séculos passados, com todo o estilo colonial e ruas de bloquetes.

Além das igrejas e do centro histórico, outros locais merecem ser visitados em Luziânia. Assim, segue um breve levantamento dos principais pontos culturais e turísticos da cidade:

1. Casa da Cultura Rui Carneiro;

2. Centro Cultural José Dilermando Meireles;

3. Praça Raimundo de Araújo Melo (Praça das Três Bicas);

4. Praça Evangelino Meireles;

5. Centro de Cultura e Convenções Professora Abigail Brasil da Silveira;

6. O Cristo Redentor.

Dentre os patrimônios imateriais de Luziânia estão às festas religiosas que atraem muitos visitantes para lá, normalmente no mês de maio acontece a Festa do Divino Espírito Santo e entre setembro e outubro a Festa de Nossa Senhora do Rosário e São Benedito, que são comemoradas juntas, devido à proximidade das datas dos dois santos. O dia de São Benedito é cinco de outubro e Nossa Senhora do Rosário sete de outubro.

As festas populares e tradicionais sempre tiveram um papel de destaque no desenvolvimento da cultura local, que teve uma história repleta de celebrações e tradições marcadas por forte influência da igreja, especialmente a católica. Como cita Marina Mello e Souza (1994) o vetor cultural do processo de acomodação então iniciado, foram às festas tradicionais, em especial a do Divino, culminância coletiva da ativa religiosidade popular. Essas celebrações foram e são, até os dias de hoje, muito significativas para a cultura popular do Estado de Goiás, especialmente em pequenas cidades, como Luziânia.

No artesanato, a cidade tem forte influência goiana e religiosa, o que pode ser constatado nas esculturas de santos em madeira, na fabricação de violinos, nas peças de barro, nas pinturas, e tantos outros trabalhos feitos por artesãos Luzianiense. Na Loja do Artesão, tem uma exposição do artesanato regional, funcionando todos os dias. Tem também a Oficina de Artes que atua com cursos permanentes de desenho e pintura. E a Casa da Cultura, que além de abrigar vários objetos, realiza encontros culturais.

Na culinária, Luziânia também tem suas especificidades. Ao provar a comida do município é nítida a presença da culinária goiana e portuguesa, não só no modo de fazer os alimentos, mas também no modo de servir. Características estas que 
também herdou dos seus colonizadores. Na realização de festas tradicionais sempre se encontra muita fartura de comida e o uso da agropecuária local. Soma-se a tudo isso, mais uma variação de sabores com galinha caipira, carne de porco, pequi, quiabo, leite, mandioca, milho, guariroba, hortaliças e aguardente.

Há o uso de um fruto tradicional da região para a fabricação de um doce típico e famoso na cidade, a marmelada. É um doce tradicional, com origem portuguesa, de destaque na cultura luzianiense, e que começou a ser produzido por escravos, em comunidades quilombolas, há mais de dois séculos. Até os dias de hoje vem sendo feito de modo artesanal, seguindo uma receita que é repassada de pai para filho em quatro fazendas de Luziânia e na sua vizinha Cidade Ocidental. Para que a tradição sobreviva, ela depende da mão de obra e dos conhecimentos dos descendentes de escravos.

Este patrimônio imaterial de Luziânia foi registrado em seu livro do tombo de registro dos saberes, que atualmente encontra-se na Casa da Cultura da cidade. Lá está descrito o passo a passo para a fabricação do doce.

Em relação aos patrimônios naturais, a cidade possui ainda um promissor potencial turístico. O Lago do Corumbá, a Cachoeira das Três Vendas, o Morro da Canastra, e o Rego das Cabaças (que possui uma história riquíssima para a cultura local) são patrimônios naturais de Luziânia, que mesmo tendo potencial para atrair turistas, ainda não são aproveitados pelos gestores com o seu devido valor.

Estes locais poderiam se tornar referencias no turismo da cidade, não só por sua beleza natural, como também por sua história. $O$ rego das cabaças, por exemplo, foi um canal aberto por escravos no século XVIII, com o intuito de levar água até o arraial na época da mineração, até os dias de hoje surpreende pela forma como foi feito.

Parte-se do pressuposto que as cidades históricas brasileiras se tornam obras de arte concreta e coletiva com o passar dos anos, Everaldo Batista da Costa e Valdir A. Steinke (2013, p. 165) afirmam que "toda cidade faz-se produto da história, do vir a ser universal que a constitui enquanto obra de arte, coletiva ou particularmente. As cidades antigas brasileiras são tratadas desta forma - como cidades históricas [...]", entendendo as cidades históricas como:

Cidade histórica é aqui apresentada como objeto concreto e simbólico do vir a ser de um território que é material e é imaginado; mescla e síntese de lugares e paisagens em movimento histórico concreto e ideativo - pois, também, mítico; é embrião, sede e centro de um processo civilizatório que guarda, em germe, a instituição urbana em si, por meio de trânsitos com o rural. (COSTA E STEINKE, 2013, p. 166).

Dentro dessa concepção, pode-se afirmar que Luziânia é uma cidade histórica, 
concreta e simbólica que, desde a sua fundação até a inauguração de Brasília, em 1960, passou por grandes mudanças, tendo sua cultura fortemente influenciada por elas. Tormin (2004) diz que Luziânia foi um dos municípios mais diretamente atingido por essas transformações na região, sofrendo impactos físicos, sociais, espaciais e culturais de toda ordem.

\section{CONSIDERAÇÕES FINAIS}

Luziânia está localizada no centro-oeste brasileiro, no estado de Goiás, entorno do Distrito Federal. Com mais de 200 anos, conta com um passado repleto de fatos significativos para a história do Planalto Central. Possui um rico patrimônio histórico, que inclui não só seus monumentos arquitetônicos, mas também suas manifestações artísticas, culturais e gastronômicas. "Suas raízes no período colonial, a mantiveram por muitos anos como um retrato de cidade barroca (TORMIN, 2004).".

Embora possua uma rica história cultural, os moradores da cidade não sabem lidar com a atual situação de seus patrimônios e, menos ainda, compreender o significado e a importância em ter esses bens preservados. Por isso, o município de Luziânia foi escolhido como objeto deste estudo, por se tratar de uma cidade histórica, com um rico patrimônio, tangível e intangível, que fazem parte do acervo cultural da cidade e que, ao longo dos anos, foram descaracterizados e menosprezados por parte de moradores e gestores, que não apenas ignoram seu valor como patrimônios históricos, mas também não reconhecem estes bens como de grande importância para a perpetuação da cultura local.

Pode-se afirmar que os patrimônios de Luziânia estão abandonados e veem sendo desprezados pelos planejadores e representantes públicos por muitos anos e, até os dias de hoje, pouco tem sido feito no sentido de agregar valores a estes patrimônios. Atualmente o patrimônio material do município conta apenas com a proteção do tombamento estadual e continua sendo negligenciado no seu conjunto pelo IPHAN. Embora o imaterial não conte com esse tipo de proteção governamental, ele se mantém vivo por contar com a proteção do povo, já que parte da comunidade luzianiense ainda tem a preocupação de preservar estes patrimônios.

Assim, esta pesquisa partiu da hipótese de que a cultura e o patrimônio histórico-cultural de Luziânia podem servir, dentre outros aspectos, para que a sociedade luzianiense possa repensar seus significados, suas atitudes e anseios no presente, 
assim como o que almeja para o seu futuro. Isso acaba gerando um reforço na sua identidade, como fator de grande importância para o sentimento de pertencimento, já que esta identidade se localiza no espaço e no tempo simbólico, Hall (2006) acredita que as culturas nacionais podem ser fontes de identidade cultural.

Logo, torna-se essencial conhecer o patrimônio histórico-cultural de Luziânia e, com isso, contribuir para a sua divulgação e utilização como agente no desenvolvimento do potencial turístico do município. É fundamental o reconhecimento dos valores e características culturais que possam ser trabalhadas pela atividade turística, como meio de integração entre história, memória, cultura e turismo, pois como Peter Burns (2002, p. 92) afirma, há a necessidade de "um conhecimento mais profundo sobre as consequências da interação entre as sociedades que geram e as que recebem turistas".

A relação entre os patrimônios materiais e imateriais é nitidamente perceptível nos bens culturais de Luziânia. A cidade possui patrimônios tangíveis e intangíveis que se fundem e que podem ser vistos ao andarmos pela cidade, principalmente no centro histórico. Estes patrimônios agregam valor à cultura da cidade e possuem forte poder de atratividade para o turismo cultural.

\section{REFERÊNCIAS}

AGUIAR, Marina. R.; DIAS, Reinaldo. Fundamentos do Turismo: conceitos, normas e definições. Campinas: Editora Alínea, 2002.

AMADO, J.; FERREIRA, M. M. Usos e Abusos da História Oral. Rio de Janeiro: Fundação Getúlio Vargas, 1996.

BENI, Mário Carlos. 0 conceito de sustentabilidade na política de turismo e meio ambiente. In: Revista de Administração, v. 33, n. 4, p. 53-55, out./ dez. São Paulo, 1998. Disponível em: < http://www.rausp.usp.br/download.asp?file=3304053.pdf >. Acesso em: 20 jun. 2013.

BRASIL, Constituição (1988). Constituição da República Federativa do Brasil.

Brasília, DF, Senado, 1998.

BRASIL, Ministério do Turismo. Diretrizes para o desenvolvimento do turismo cultural. 2. ed. Brasília: MTur, 2008. 
BURNS, Peter. Turismo e Antropologia: uma introdução. São Paulo: Chronos, 2002. COSTA, Everaldo Batista da. Totalidade urbana e totalidade mundo - as cidades coloniais barrocas face à patrimonialização global. Tese (Doutorado em Geografia). FFLCH-USP, São Paulo, 2011.

COSTA, Everaldo Batista da; STEINKE, Valdir A. Cidades históricas do estado de Goiás, Brasil: uma agenda de pesquisa. Ateliê Geográfico - Goiânia-GO, v. 7, n. 2, p.164195, ago/2013.

CUCHE, Denys. A noção de cultura nas ciências sociais. 2 ed. Bauru: EDUSC, 2002. CRUCES, F. Problemas en torno a la restitución del patrimonio. Una visión desde la antropología, em Política y Sociedad. No 27, 1998.

DELGADO, Lucília A. N. História Oral - memória, tempo, identidades. Belo Horizonte: Autentica, 2010.

DENCKER, Ada de Freitas M. Métodos e Técnicas de Pesquisa em Turismo. 2 ed. São Paulo: Futura, 1998.

FERREIRA, Maria Letícia Mazzuchi. Patrimônio: Discutindo alguns conceitos. In: Diálogos, DHI/PPH/UEM, v. 10, n. 3, p. 79-88, 2006.

FONSECA, Maria Cecília Londres. Para Além da Pedra e Cal: Por uma concepção Ampla de Patrimônio Cultural. In: ABREU, R.; CHAGAS, M. (orgs.). Memória e patrimônio: ensaios contemporâneos. Rio de Janeiro: DP\&A, 2009.

FUNARI, Pedro Paulo; PINSKY, Jaime (orgs.). Turismo e patrimônio cultural. São Paulo: Contexto, 2003.

GEERTZ, Clifford. A interpretação das culturas. Rio de Janeiro: LTC, 2008.

GONÇALVES, José Reginaldo. Patrimônio, natureza e etnicidade: reinvenções da cultura açoriana. Anais do VIII Congresso Luso-Afro-Brasileiro de Ciências Sociais: A questão social no novo milênio, Universidade de Coimbra. Coimbra, Portugal, 2004.

GOODEY, Brian. A interpretação do Sítio Turístico: desenho e atividade. In: MURTA, S. M.; ALBANO, C. (orgs). Interpretar o patrimônio: um exercício do olhar. Belo horizonte: Ed UFMG. Território Brasilis, 2002.

HALL, Collin Michael. Planejamento turístico: políticas, processos e relacionamentos. Tradução de Edite Sciulli. 2. ed. São Paulo: Contexto, 2004.

HALL, Stuart. A identidade cultural na pós-modernidade. Guaracira Lopes Louro 11. Ed. - Rio de Janeiro: DP\&A, 2006. 
JAFARI, J. La cientifizacion del turismo: estúdios y perspectivas en turismo. Buenos Aires: CIET, Vol. 3, no1, p.7-36, 1994.

MELLO E SOUZA, Marina. Parati: a cidade e as festas. Rio de Janeiro: Ed. UFRJ/ Tempo Brasileiro, 1994.

MOESCH, Marutschka Martini. Epistemologia social do turismo. Tese (Doutorado em Relações Públicas, Propaganda e Turismo). Escola de Comunicação e Arte. Universidade de São Paulo, Brasília, 2004.

MURTA, Stela Maris. Turismo histórico-cultural: parques temáticos, roteiros e atrações âncora. In: MURTA, S. M.; ALBANO, C. (Orgs.). Interpretar o patrimônio: um exercício do olhar. Belo Horizonte: UFMG; Território Brasilis, 2002.

ONFRAY, Michel. Teoria da Viagem. Porto Alegre, L\&PM, 2009.

OLIVEN, Ruben George. Patrimônio intangível: considerações iniciais. In: Memória e patrimônio: ensaios contemporâneos. ABREU, R; CHAGAS, M. (orgs.). Rio de Janeiro: DP\&A Editora, 2009.

PEIXOTO, Paulo. Centros históricos e sustentabilidade cultural das cidades: Intermediários culturais, espaço público e cultura urbana. Portugal: Centro de Estudos Sociais, 2003.

PEREIRA, Bruno. T. da S; SILVA, Luiz. F. O; PERINOTTO, André. R. C. Festejo de São Francisco: análise sobre uma alternativa de desenvolvimento do Turismo Religioso em Parnaíba (Piauí, Brasil). Turismo \& Sociedade. Curitiba, v. 4, n. 2, p. 363-380, outubro de 2011.

PORTUGUEZ, Anderson Pereira. Turismo, memória e patrimônio cultural. São Paulo, Editora Roca, 2004.

RUSCHMANN, Doris Van de Meene. Turismo e Planejamento Sustentável: A Proteção do Meio Ambiente. Campinas, São Paulo: Papirus, 1997.

TORMIN, Cassiana Vaz. Um lugar e suas raízes. O pensamento político em Luziânia/ GO. Dissertação (Mestrado em Geografia). Departamento de Geografia, Instituto de Ciências Humanas, Universidade de Brasília, Brasília, 2004, mímeo, 140 p.

UNESCO. Recomendação de Paris - Convenção para a Salvaguarda do Patrimônio Cultural Imaterial. Paris, 2003. Disponível em: <http://portal.iphan.gov.br/portal/ baixaFcdAnexo.do?id=271 >. Acesso em: 27 de jun. 2012. 